\title{
SMALL SCALE IN-SITU BIOREMEDIATION OF DIESEL CONTAMINATED SOIL - SCREENING LIFE CYCLE ASSESSMENT OF ENVIRONMENTAL PERFORMANCE
}

\author{
Joseph Akambih Tajam \\ Anders Jonsson \\ Morgan Fröling \\ Mid Sweden University, Östersund, Sweden
}

\begin{abstract}
Spillage of diesel oil and other petroleum products is a commonly creating need for site remediation of contaminated soils. In Sweden the most common remediation action is excavation of the contaminated soil and off site biological treatment by composting. However, a number of small sites spread out in rural areas end up low on priority lists, and will not be attended to within foreseeable future if ever. For such areas a low cost, easy to apply remediation techniques would be of interest. Enhanced bioremediation of diesel contaminants in soil by whey addition has been demonstrated in lab scale. Whey is a by-product from cheese production. A first pilot remediation trial on an actual site in Gäddede, County of Jämtland, was started the summer of 2010. Using this site as a case study a screening life cycle assessment model has been set up. The goal of the study was to investigate the environmental performance of the whey method, to benchmark the whey method toward the excavation and composting practice and to identify environmental hot spots in the whey treatment life cycle. The study aims at establishing if further work should be put into developing the method, or if the environmental performance is such that the whey method should be abandoned. It should be noted that even with a slightly worse environmental performance compared to other remediation alternatives whey treatment could still be of interest, since the small scale sites in rural areas we talk about here otherwise most often would not be attended to. Results from the screening life cycle assessment indicate a rather good environmental performance of the whey method, partly depending on impact category considered. For the whey method, impacts from farming activities in the milk production chain allocated to the whey give significant contributions. Transportation gives important impacts from both the whey method and the excavation and off site composting, thus logistics should always be considered and optimized. The whey onsite treatment could be an interesting alternative for bioremediation especially at sites that would not otherwise be treated, due to small size or remote location.
\end{abstract}

\section{KEYWORDS}

Bioremediation, diesel contamination, whey treatment, composting, LCA 


\section{INTRODUCTION}

Petroleum products are among the most widely used chemicals in the world today [1, 2]. Leakages, accidental and deliberate spills become unavoidable when we look at the massive quantity of fuel used, stored, transported et c. The European Environmental Agency (EEA), [3] estimates that at least 250,000 sites with contaminated soil in EEA member countries require cleanup. In Sweden, there are approximately 80,000 sites where operations are assumed to have caused contamination [4].

Based on the physical location of the remedial action remediation technologies can be divided into two groups, in-situ and ex-situ remediation [5]. In the former, the treatment of the contaminated media takes place by actions that target the contamination in its actual location in the subsurface. In the later, the contaminated media is removed from the site followed by a treatment which can either take place in an above ground treatment facility on-site or by treatment or disposal elsewhere, off-site.

According to a study by the Swedish EPA in 2006 excavation and transport was the clearly dominating remediation technology in Sweden [6]. This is also true locally, e.g. in the county of Jämtland [7].

However, a number of small sites spread out in rural areas end up low on priority lists, and will not be attended to within foreseeable future if ever. For such areas a low cost, easy to apply remediation techniques would be of interest. The on-site whey treatment investigated in this study might be such a method.

\section{METHODOLOGY AND CASE DESCRIPTION}

Life Cycle Assessment (LCA) is a study of environmental impacts over the life cycle of a product or service, i.e. from raw material extraction, through production, to use and disposal phase (from 'cradle to grave'). LCA has three important parts; goal and scope definition, inventory analysis and impact assessment [8]. LCA studies have been performed on remediation technologies earlier. Toffelotto et al [9] in 2005 carried out a LCA study on ex-situ bioremediation of diesel contaminated soil. In 2007, Cadotte et al [10] use LCA in the selection of a remediation scenario for a diesel contaminated site. Lemming et al [5] reviewed 12 different studies on life cycle assessment of soil and groundwater remediation in 2009. Similarly Suèr et al [11] in 2004 made a literature review on LCA for site remediation. A common conclusion from these reports is that transport of excavated soil often contributes significantly to the total environmental impact of any off site remediation technology, especially at longer transport distances.

\subsection{Goal and scope}

In this study the environmental performance of on-site bio-remediation of diesel contaminated soil in a rural area using the whey method will be investigated and compared to excavation and off-site composting using screening LCA methodology. Since the whey method is still under development one objective is to evaluate whether it is of interest from environmental impact point of view to continue to develop the whey method. This study delimited to a specific contaminated site in Gäddede, northern part 
of the county Jämtland, Sweden. The study is theoretical, a "what if" type of study, since the tests with the whey method at this site has not yet been finalized.

The functional unit of this study was the treatment of $5 \mathrm{~m}^{3}$ of contaminated soil reaching a diesel concentration of $500 \mathrm{mg} / \mathrm{kg} \mathrm{dw}$ (upper limit in generic guidelines for "non sensitive areas"). For impact assessment the results are characterized into global warming potential (GWP), acidification potential (AP), eutrophication potential (EP) and photo oxidant creation potential (POCP) using characterization indices based on $[8]$.

\subsection{The contaminated area}

The contaminated site is an area where a diesel tank with a volume of $15 \mathrm{~m}^{3}$ has been situated, established some time in 1960s, with no surface impoundment. This tank was used for filling up trucks etc. by several haulers until a tank station was established in the area.

The contaminated area was survey by SWECO Environment in 2008 [12]. Six drilling samples were taken. The contaminated site is about $10 \mathrm{~m}^{2}$ in area and about $0.5 \mathrm{~m}$ in depth. The sample with highest concentration of diesel contaminants (C5-C35) was $2,200 \mathrm{mg} / \mathrm{kg} \mathrm{dw}$. No groundwater encountered in connection with drilling, and the property is not within any water source protected area.

\subsection{The whey on-site treatment and the excavation and off site composting methods}

Addition of whey to increase biological activity in soil for remediation purposes has been studied in laboratory scale by Östberg et al (2006) [13] and Östeberg et al (2007) [14]. Whey is a by product from cheese production. Based on the mentioned laboratory results a scale up treatment plan for the Gäddede site was developed. A pilot test of the whey method in the site of Gäddede started during this study, but is not yet finalized. A report on parallel laboratory tests on contaminated soil from this site is reported at this conference by Vilches et al (2010) [15]. Whey is added together with commercial fertilizer to avoid macronutrient deficit. Since the biological activity only take place when it is warm enough the total treatment time is estimated to two summers.

The alternative treatment assumed in this study is to excavate the $5 \mathrm{~m}^{3}$ of contaminated soil at the site in Gäddede, transport it to the waste treatment site in Gräfsåsen, Östersund, Sweden and there compost the soil in windrows after mixing the soil with manure. The windrows are turned using an excavator and when the concentrations of contaminants are low enough the compost is used as top cover of a landfill.

\subsection{Scenario descriptions and inventory data}

\subsubsection{The whey scenario}

Figure 1 illustrates a simplified model of the life-cycle process flow diagram for the whey treatment scenario. 


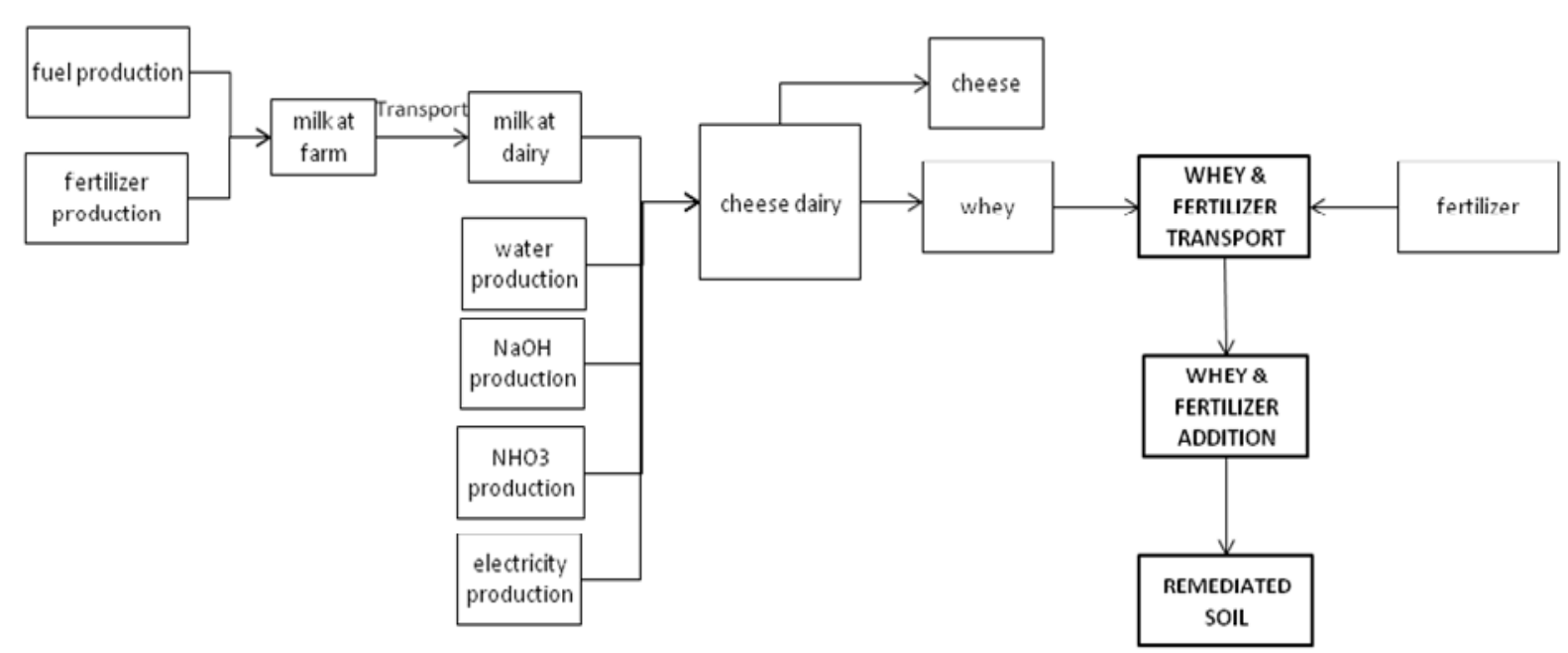

Figure 1. The life cycle inventory model of the whey scenario.

The hydrocarbon pollution in the $5 \mathrm{~m}^{3}$ soil to be treated (over an area of $10 \mathrm{~m}^{2}$ ) was assumed to be the same in the whole mass of soil; 2,200 $\mathrm{mg} / \mathrm{kg} \mathrm{dw}$ (SWECO, 2008). Comparisons with laboratory results $[13,16]$ indicate that an addition of $210 \mathrm{mg} \mathrm{dw}$ whey/kg diesel polluted soil might give a sufficient reduction in diesel oil contamination to reach the higher target value of $500 \mathrm{mg} / \mathrm{kg} \mathrm{dw}$ [4]. This gives a calculated need of about $2 \mathrm{~kg} \mathrm{dw}$ whey, equivalent to $367 \mathrm{~L}$ of whey $(5.5 \mathrm{~g} \mathrm{dw} / \mathrm{L})$ for the area to be treated. The laboratory tests also indicate that subsequent additions of whey will give a better degradation compared to one large addition, and eight additions (46 L of wet whey per addition) spaced out with 14 days in between was assumed to be a good practice. The total time needed for the degradation is from the laboratory tests estimated to 167 days. Since on-site biodegradation will only take place when it is warm enough $[14,17]$ the degradation has been assumed to take place during two summer months each year for two years. To not have the biodegradation limited by macronutrient deficiencies we assume an addition of commercial fertilizer. The amount of fertilizer needed is scaled from a desired C:N:P molar ratio of 117:11:1 [13] and from the total amount of carbon present in the polluted soil (approximated with the polluting diesel amount). The molar ration above was therefore recalculated into $\mathrm{N}: \mathrm{P}$ weight ratio 4:1. YaraMila 18-4-14 was the commercial fertilizer assumed (with 14 being the weight ratio for potassium). The amount of nutrients needed would require a one-time addition of $1.5 \mathrm{~kg}$ YaraMila 18-4-14. During the remediation process whey and fertilizer are assumed to be manually added to the contaminated area. The whey will be added $46 \mathrm{~L}$ every 14 day over a period of two subsequent summers.

Whey is a by-product of cheese production. For the intended bioremediation we need whey $2 \mathrm{~kg} \mathrm{dw}$ whey. Data on cheese and whey production was obtained from Milko dairy in Östersund. To produce 0.9 ton of Edam cheese and 1 ton of dry whey the cheese dairy on average requires $11,000 \mathrm{~L}$ of cheese milk [18]. Inventory data was gathered to describe the use of average Swedish electricity [19], water and auxiliary chemicals [20]. Inventory data for milk production, including farming activities, transports and diary operations was based on a LCI by the Swedish Diary Association [21]. 
Since whey is a byproduct of cheese production economic allocation was used giving an allocation of $80 \%$ on cheese and $20 \%$ on whey [18]. In a sensitivity analysis the results if all production environmental impact is allocated to the whey is investigated.

The fertilizer production is described using emissions data on the production of $1 \mathrm{~kg}$ of fertilizer [22].

Whey and fertilizer will have to be transported to the contaminated site. Whey produced in Sweden by Milko AB is transported over a distance of $230 \mathrm{~km}$ from Östersund to Gäddede. Fertilizer is obtained from commercial fertilizer store and transported the same distance. Environmental impacts from the transport was calculated using emissions factors assuming a light distribution truck, Euro 2, vehicle manufactured during 1996-2000 [8].

\subsubsection{The excavation and composting scenario}

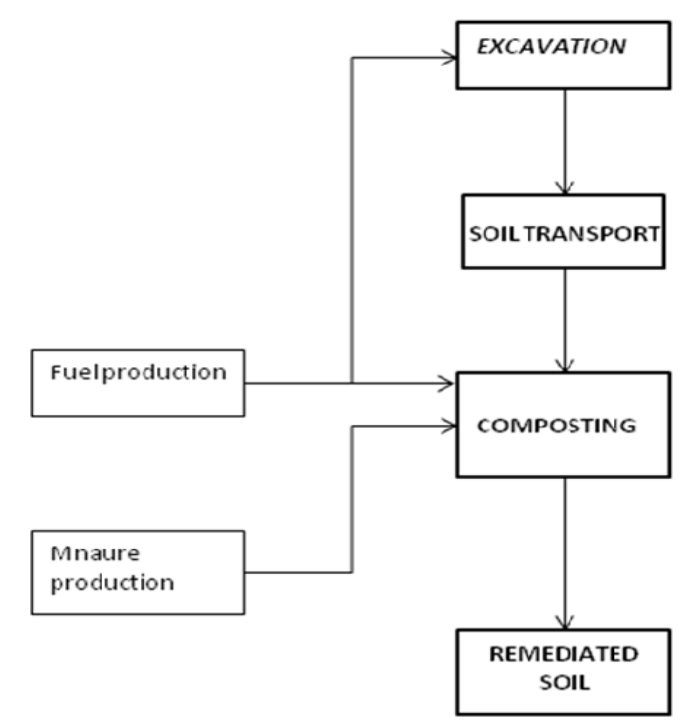

Figure 2. The life cycle inventory model of the excavation and composting scenario.

Figure 2 illustrates a simplified model of the life-cycle process flow diagram for the excavation and composting treatment scenario. Assuming a soil density of $1922 \mathrm{~kg} / \mathrm{m}^{3}$ for the $5 \mathrm{~m}^{3}$ soil to be treated (over an area of $10 \mathrm{~m}^{2}$ ) the calculated mass of contaminated soil was 9.6 ton.

Information obtained from Reaxcer, Östersund (http://www.reaxcer.se/) estimates that the Gäddede case would use a 14 ton excavator with an excavation time of 15 minutes (depending on the soil type) and required diesel amount is 2 L [23]. Tail pipe emission from the excavation was calculated by the company's environmental performance software. Production of the needed diesel oil was described by inventory data from [24]. The excavated soil will then have to be transported from Gäddede to Östersund $230 \mathrm{~km}$ 
to composting plant. We describe the impact from the transport using emission factors for a medium sized distribution truck with a payload of 8.5-14 ton, Euro class 2, produced between $1996-2000$ [8].

At Gräfsåsen, the waste treatment and landfill in Östersund, the contaminated soil is mixed with horse manure and put in windrows in a string-like arrangement. Over the period 2005 to 2009 some 2320 tons of contaminated soil and 1560 tons of manure have been received at the composting plant in Gräfsåsen, giving an average manure use of 0.67 ton/ton. For the manure transport we assume the same emission factors as for the soil transport and an average transport distance of $50 \mathrm{~km}$. The manure generations is totally allocated to the horse keeping. Every one month during the summer the windrows are mixed using a mixer mounted on a wheel loader. For this process we assume half the environmental impact from excavation in Gäddede. The use of the treated compost as cover of the land fill is not assumed to be connected to any environmental impacts.

\section{RESULTS AND DISCUSSION}

In Figure 3 the results from the whey treatment scenario and the composting scenario for the four impact categories GWP, AP, EP and POCP is shown, together with the results from the sensitivity analysis where all environmental impacts from milk production and the cheese diary are allocated to the whey.

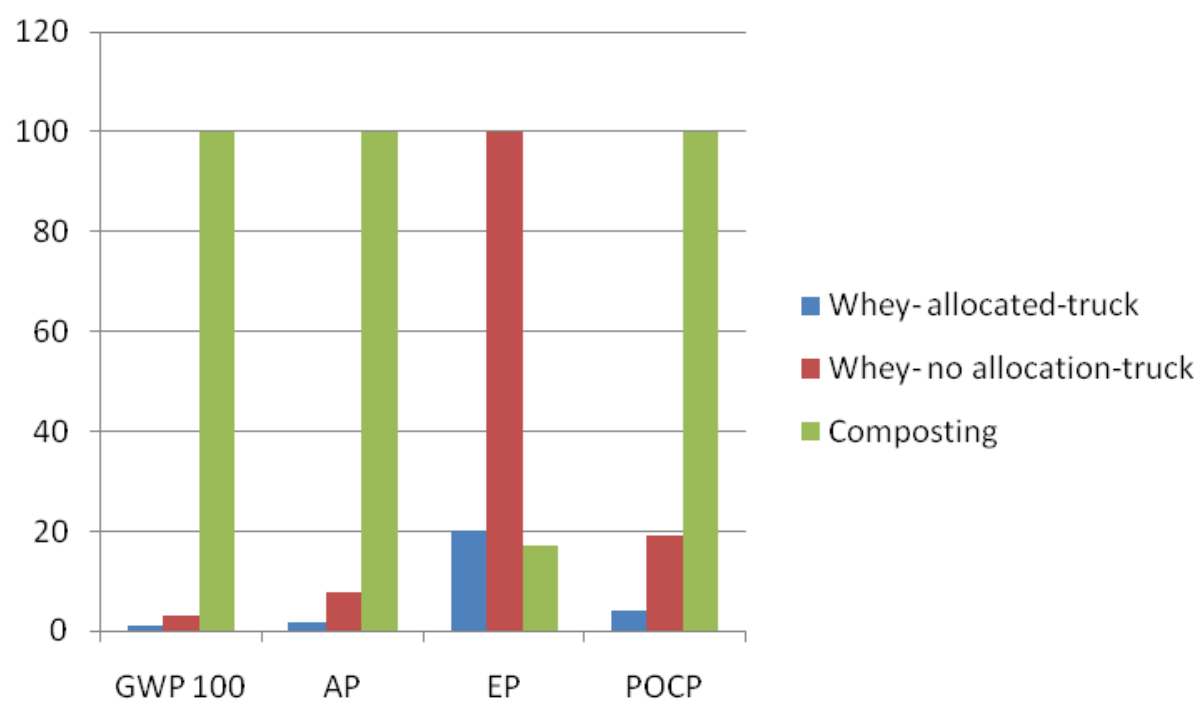

Figure 3. Results from the LCA models for the in-situ whey treatment scenario - with and without allocation of the whey production - assuming truck transport and the excavation and off-site composting scenario. Normalized data, the highest result in each category is set to $100 \%$.

For the GWP, AP and POCP impact categories the whey scenarios give lower results than the excavation and of site composting scenario, whereas the EP category shows higher results. The EP result for the whey treatment is totally dependent on the whey production chain and originates at the farm (such as nutrient runoff, ruminating cattle, 
vaporization of ammonia from manure) or by the production of materials used at the farm (such as fertilizers). The milk farm activity is the most contributing in the whey scenario for all four impact categories shown.

The most contributing activity for the composting scenario in all of the impact categories studied is the transport of the excavated soil to the composting site. Thus the transport distance is of large importance. For sites where the transport distance is much shorter, the composting scenario would come out much better. This outcome is in accordance with what has been earlier reported by Suèr et al (2004) [11] and Toffoletto et al (2005) [9], that transportation is a key element when choosing between in-situ and ex-situ remediation technology.

When comparing the allocated and the unallocated whey treatment scenarios the milkcheese chain has a rather large impact, especially for eutrophication (EP in diagram).

It should be noted that the transport of whey and fertilizer for the whey scenario is described with emission factors of a truck transport, that mean it is assumed to have the necessary whey and fertilizer as part of the load of the truck and the off-loading will be part of a delivery route where other parts of the load will be off-loaded in other places. Also the person making the eight subsequent whey additions are assumed to live or work nearby Gäddede and not transported from Östersund in each case. If the transport of whey and fertilizer would be arranged by personal car together with a person going to Gäddede for each addition of whey the results would change to those of Figure 4, with increasing GWP transport emissions. Arranging good logistics is thus very important both for the whey treatment and for the excavation and transport to off-site composting.

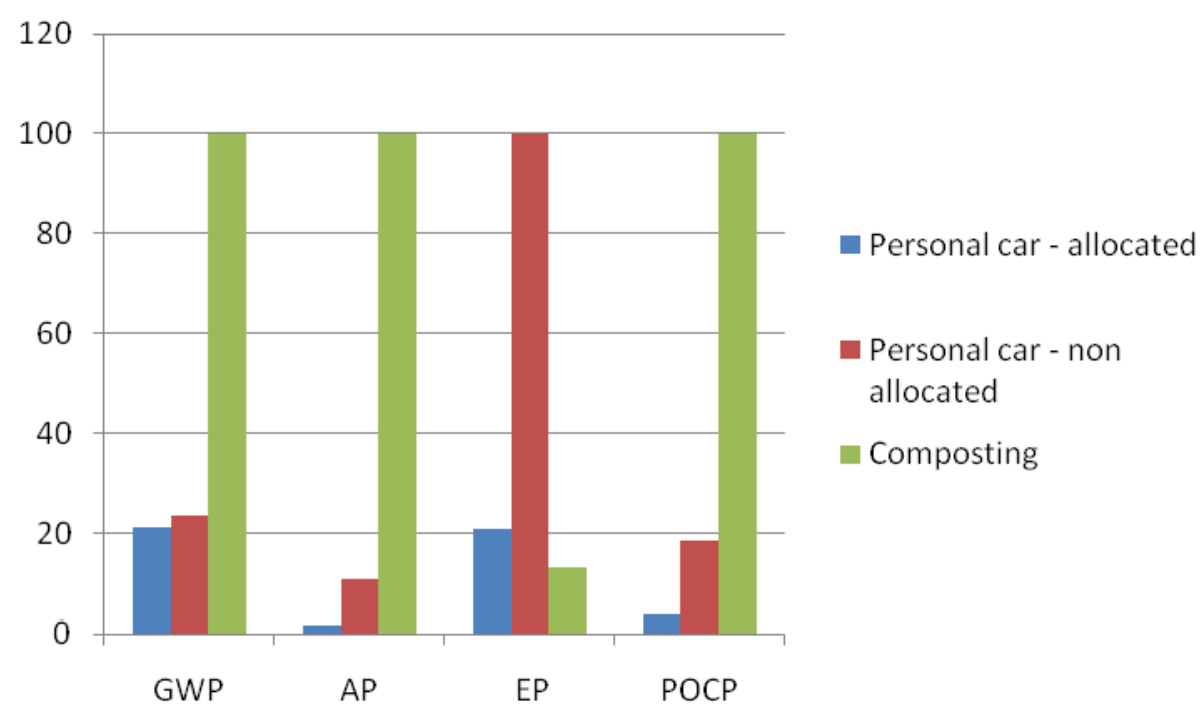

Figure 4. Results from the LCA models for the in-situ whey treatment scenario - with and without allocation of the whey production - assuming eight trips with a personal car for whey additions and the excavation and off-site composting scenario. Normalized data, the highest result in each category is set to $100 \%$. 


\section{CONCLUSIONS}

Results from screening life cycle assessment indicate a rather good environmental performance of the whey method, partly depending on impact category considered. For the whey method, impacts from farming activities in the milk production chain allocated to the whey give significant contributions. Transportation gives important impacts from both the whey method and the excavation and off-site composting, thus logistics should always be considered and optimized. The whey in-situ treatment could be an interesting alternative for bioremediation especially at sites that would not otherwise be treated, due to small size or remote location.

\section{REFERENCES}

[1] Sakar, D., Ferguson, M., Datta, R., Birnbaum, S., 2005. Bioremediation of petroleum hydrocarbons in contaminated soils: Comparison of bio solids addition, carbon supplementation, and monitored natural attenuation. Environmental Pollution, 136(1), 187-195.

[2] Sunahara, G.I., Renoux, A.Y., Thellen, C., Gaudet, C.L., Pilon, A., 2002. Environmental Analysis of contaminated sites. West Sussex, UK: John Wiley \& Sons.

[3] European Environmental Agency (EEA), 2007. Progress in the management of contaminated sites. Copenhagen: EEA, CSI 015 Assessment.

[4] Naturvårdsverket (Swedish EPA), 2008. Remediation of contaminated areas. Sweden.

[5] Lemming G., Hauschild M., Bjerg P., 2009. Life cycle assessment of soil and groundwater remediation technologies: Literature review. International journal of Life Cycle Assessment, 15(1), 115-127

[6] Naturvårdsverket (Swedish EPA), 2006. Åtgärdslösningar - erfarenheter och tillgängliga metoder. Sweden, Report 5637.

[7] Olsson, Karin, 2010. Personal communication. Miljöskyddshandläggare, samordnare, Länsstyrelsen i Jämtlands län, 83186 Östersund, Sweden. www.lansstyrelsen.se

[8] Baumman, H., \& Tillman, A., 2004. The Hitch Hiker's Guide to LCA. Lund, Sweden: Studentlitteratur.

[9] Toffoletto, L., Deschênes, L. and Samson, R., 2005. LCA of Ex-Situ Bioremediation of Diesel-Contaminated Soil. International journal of Life Cycle Assessment 10(6), 406 $-416$.

[10] Cadotte, M., Deschênes, L. and Samson, R., 2007. Selection of a Remediation Scenario for a Diesel-Contaminated Site Using LCA. journal of Life Cycle Assessment 12 (4) 239-251.

[11] Suèr, P., Nilsson-Påledal, S. and Norrman, J., 2004. LCA for Site Remediation: A

Literature review. Soil \& Sediment Contamination, 13:415-425, 2004.

[12] SWECO Environment AB, 2008. Miljöteknisk markundersöking av dieselanläggning. Östersund-Sweden. Report T0815089.

[13] Östberg Thomas L., Josson Anders P., Lundström Ulla S., 2006. Accelerated biodegra-dation of n-alkanes in aqueous solution by the addition of fermented whey. International Biodeterioration and Biodegradation, 57, 190-194. 
[14] Östberg Thomas L., Josson Anders P., Lundström Ulla S., 2007. Enhance degradation of n-Hexadecane in diesel fuel contaminated soil by the addition of fermented whey. Soil and sediment, an international journal, 16(2), 221-232.

[15] Vilches, A.P., Bylund, D. and Jonsson, A, 2010. Enhanced natural biodegradation of diesel fuel contaminants in soil by addition of whey and nutrients. Proceedings of Linnaeus ECO-TECH '10, November 22-24. 2010, Kalmar, Sweden.

[16] Jonsson, Anders, 2010. Unpublished data.

[17] Fröling, M. and Berg, P. E. O, 1996. Oily Waste Composting. Proceedings of the AUZO'96 International Conferece on Analysis and Utilisation of Oily Wastes, September 8-12, 1996, University of Gdansk, Poland. Available at: http://publications.lib.chalmers.se/records/fulltext/local_24666.pdf

[18] Åström, Staffan, 2010. Personal communication. R\&D Department, Milko. Östersund, Sweden, 14 April 2010.

[19] Table App 1.1, Annex 1 in [8]

[20] Berlin, J., 2002. Environmental life cycle assessment (LCA) of Swedish semi-hard cheese. International Dairy Journal, 12, 939-953.

[21] Swedish Dairy Association, 1999. Milk and the Environment. Sweden. Available from http://www.svenskmjolk.se/In-English/Downloads [Accessed 16 April 2010].

[22] CPM, 1996. SPINE LCI dataset: N-fertilizer production. Available at www.cpm.chalmers.se/CPMDatabase

[23] Dahlin, Mattias, 2010. Personal communication. April 22, 2010. Reaxcer AB, Hagvägen 10, 83148 Östersund, Sweden. www.reaxcer.se.

[24] CPM, 1996. SPINE LCI dataset: Diesel production. Available at www.cpm.chalmers.se/CPMDatabase 